ORIGINAL ARTICLE

\title{
Postnatal weight loss in term infants: what is "normal" and do growth charts allow for it?
}

\author{
C M Wright, K N Parkinson
}

Arch Dis Child Fetal Neonatal Ed 2004;89:F254-F257. doi: 10.1136/adc.2003.026906

See end of article for authors' affiliations .....................

Correspondence to: Dr Wright, PEACH Unit, QMH Tower Yorkhill

Hospitals, Glasgow G3

8SJ, Scotland, UK;

charlotte.wright@

clinmed.gla.ac.uk

Accepted 2 July 2003

Background: Although it is a well known phenomenon, limited normative data on neonatal weight loss and subsequent gain are available, making it hard to assess individual children with prolonged weight loss.

Objective: To establish, using data from a large prospective population based cohort study, norms and limits for postnatal weight loss and its impact on current growth reference charts.

Method: A cohort of 961 term infants were recruited at birth and followed using parental questionnaires and community nursing returns. Routine weights were collected for half the cohort at 5 days and for all at 12 days and 6 weeks.

Results: Less weight loss was seen than the 3-6\% suggested by previous studies, but one in five infants had not regained their birth weight by 12 days. Those lightest at birth showed least weight loss. Twenty six (3\%) children had more than $10 \%$ weight loss, but none showed evidence of major organic disease. Actual weights in the first fortnight are half to one centile space lower than growth charts suggest, while birthweight centiles for children born at 37 weeks were two centile spaces lower.

Conclusions: Neonatal weight loss is brief, with few children remaining more than $10 \%$ below birth weight after 5 days. Growth charts are misleading in the first 2 weeks, because they make no allowance for neonatal weight loss.

$\mathrm{B}$ abies gain weight faster in early infancy than at any subsequent age, and judging whether weight gain is within normal limits during this period can be difficult. This is made even harder by the fact that most infants show a period of weight loss immediately after birth, before this rapid gain begins.

Although it is a well known phenomenon, limited normative data on neonatal weight gain are available. These suggest that, on average, infants lose $4-7 \%$ of their birth weight ${ }^{1-3}$ and begin to regain weight by day $3 .{ }^{45}$ However, these studies were not large enough to estimate accurately the normal limits for weight loss in the first few days of life. Growth charts are designed to describe how a measurement at any particular age compares with other children of the same age and sex. However, they are also commonly used to assess the growth trajectory of individual children over time. Much improved infancy growth charts are now available both in Britain and the United States, which do not show the major discrepancies seen in earlier versions, ${ }^{6}$ but neither appear to make any allowance for immediate postnatal weight loss. Data from our large cohort study offered the opportunity to establish norms for neonatal weight variation and to explore how these affect interpretation of current infancy weight charts.

\section{METHOD}

The Millennium Baby Study is a prospective study of feeding and growth in infancy. Subjects eligible for recruitment were babies born to residents of Gateshead, an urban borough in the North of England. The study received approval from the Gateshead local research ethics committee. All babies born in specified recruiting weeks between June 1999 and May 2000 were invited to join the study, usually while still on one of the two maternity units serving the area. On recruitment, parents signed a consent form and were issued with a Personal Child Health Record. This included forms to be returned by health staff. Community midwives make a home visit at 5 days to collect a blood sample for metabolic screening. They do not routinely weigh babies in the first week, but half agreed to weigh babies in the study at 5 days for research purposes. Health visitors are community based nurses with responsibility for child health surveillance and parental support. They make their primary visit at age 2 weeks, when babies are usually weighed, so all were asked to return a weight.

Basic birth and other information was collected from parents at recruitment, and thereafter parents received postal questionnaires at intervals through the first year, the first at age 6 weeks. In this, parents were asked to transcribe the weight from the routine 6-8 weeks health check, with the date collected, on to their questionnaire, as well as all other baby clinic weights in their Personal Child Health Record. At the end of the study ( 13 months), a copy of the weight recording page was retrieved from the child's record.

After data collection was completed, all weights available for each child were collated and duplicates deleted. Weights were transformed into standard deviation scores (SDS) compared with both the UK $1990^{7}$ and the new US Centre for Disease Control growth references. ${ }^{8}$ All extreme SDSs were checked against other weights held on the child and corrected where possible. About 100 (out of 13 000) plainly erroneous weights-for example, where one value was inconsistent with other weights around the same age-were deleted. For each child, the weight nearest to each target age ( 5 days, 12 days, 7 weeks) and within a previously stated range (4-7, 10-18, 29-70 days) was identified.

Postcode at birth was used to identify the Townsend deprivation score ${ }^{9}$ corresponding to each child's census enumeration district, as a measure of relative deprivation.

\section{RESULTS}

A total of 1254 babies were born to residents of Gateshead in 34 recruiting weeks. Of these, 1011 mothers of 1029 (82\%) 


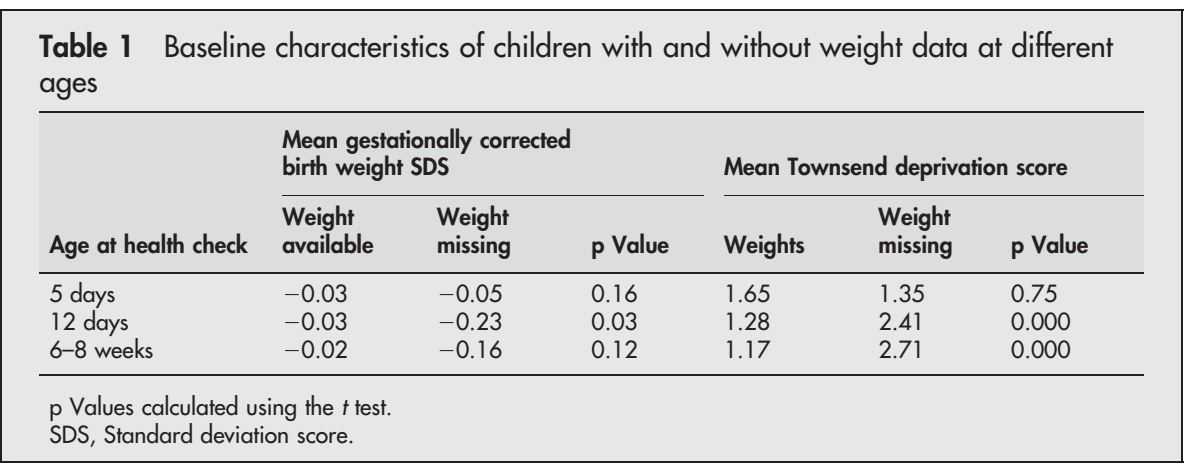

babies agreed to join the study. Of these, 961 were born at term (gestation $\geqslant 37$ weeks) and are the subjects of this analysis. All but 36 were singleton births, and 475 (51\%) were breast fed at birth. The participating midwife teams returned weights at 5 days for $63 \%$ of the babies compared with only $33 \%$ in non-participating teams. The mean weight SDS and age at measurement were very similar for both groups, and there was no difference in birth weight and little difference in levels of deprivation for those weighed or not weighed (table 1). Therefore all the weights were used: 490 weights from $51 \%$ subjects returned between age 5 and 7 days, with $86 \%$ returned on day 5 . Weights were returned by health visitors for $838(87 \%)$ subjects at median age (interquartile range (IQR)) 12 (11-14) days and by parents for $816(85 \%)$ at median (IQR) age 48 (44-54) days. The small proportion not weighed at these ages did have higher levels of deprivation and a trend to lower birth weights (table 1).

At 5 days, the mean weight loss was $50 \mathrm{~g}$, only just over $1 \%$ below birth weight. A third had already regained their birth weight, but $3 \%$ were more than $10 \%$ below (table 2 ). At 12 days, subjects had gained nearly $200 \mathrm{~g}$ on average. Over $80 \%$ had now regained their birth weight, but $1.7 \%$ were still more than $10 \%$ below. By age 6 weeks, all subjects had regained their birth weight.

The degree of initial weight loss (or gain) was most strongly predicted by initial weight, with subjects with low birth weights showing little or no weight loss. Subjects with birth weights below the 9th centile showed a mean (SD) gain of 24 (145) g at 5 days, with only $31(50 \%)$ still below birth weight. Those above the 91st centile at birth lost 180 (225) g with $35(78 \%)$ still below birth weight $(\mathrm{p}<0.001$, analysis of variance). Twenty six children were more than $10 \%$ below their birth weight when measured at either 5 or 10-14 days (or both). Of these, five were admitted to hospital within the first 3 weeks, but none proved to have major medical problems. Most had recovered by the age of 6 weeks, but at that stage a third still had a weight gain below the 5 th centile for age.

Breast fed infants showed less mean weight gain and were significantly more likely to lose more than $10 \%$ of birth weight, but this trend was no longer significant after adjustment for birth weight, which was significantly higher in breast fed infants.

When expressed as weight SD scores, compared with either UK or US standards, mean values dropped away markedly by 5 days of age and remained well below the 50th centile at 12 days, although close to expected values by the age of 6 weeks (table 2, fig 1). Without adjustment for gestation, the subjects as a group appeared to have below average birth weights compared with either standards, a discrepancy that was most pronounced in those of lower term gestations (fig 2). However, there was a good fit to the UK reference when birth weight was adjusted for gestation.

\section{DISCUSSION}

Postnatal weight loss is a well known but little studied phenomenon. It represents mainly fluid $\operatorname{loss}^{10}$ but may also involve loss of fat stores during the establishment of milk feeding. ${ }^{11}$ Our findings suggest that this weight loss is usually of brief duration, with a rapid acceleration within the first week. However, if plotted on growth charts, all babies appear to fall in weight and remain half to one centile space lower for the first fortnight.

The children included in this study came from just one Northern English town, but proved highly comparable at birth and age 6 weeks to both British and US reference standards. At day five, only about half the cohort were

Table 2 Weight characteristics at different examination ages

\begin{tabular}{|c|c|c|c|c|}
\hline & 0 & $5(4-7)$ & $12(10-18)$ & $48(29-70)$ \\
\hline Number of weights & 959 & 490 & 839 & 816 \\
\hline Actual age* & 0 & $5(5-5)$ & $12(11-14)$ & $48(44-54)$ \\
\hline Weight change (g) & - & $-50(171)$ & $+193(246)$ & $+1479(468)$ \\
\hline$\%$ weight change & - & $-1.3(5.0)$ & $+6.0(7.6)$ & $+45(16.3)$ \\
\hline $\begin{array}{l}\text { Weight SDS compared with UK } \\
1990 \text { reference } \dagger\end{array}$ & $-0.19(1.1)$ & $-0.56(1.02)$ & $-0.49(0.99)$ & $-0.03(1.00)$ \\
\hline $\begin{array}{l}\text { Weight SDS compared with US } \\
\text { reference } †\end{array}$ & $-0.08(0.99)$ & $-0.42(0.95)$ & $-0.36(0.97)$ & $+0.17(0.95)$ \\
\hline Regained birth weightł & - & $34 \%(165)$ & $81 \%(679)$ & $100 \%(816)$ \\
\hline More than $5 \%$ below birth weightł & & $17 \%(82)$ & $3.8 \%(32)$ & 0 \\
\hline More than $10 \%$ below birth weight & - & $3.3 \%(16)$ & $1.7 \%(14)$ & 0 \\
\hline
\end{tabular}

The target examination age is given in days with the range in parentheses.

${ }^{*}$ Median (interquartile range).

†Mean (SD).

†Percentage (number).

SDS, Standard deviation score. 


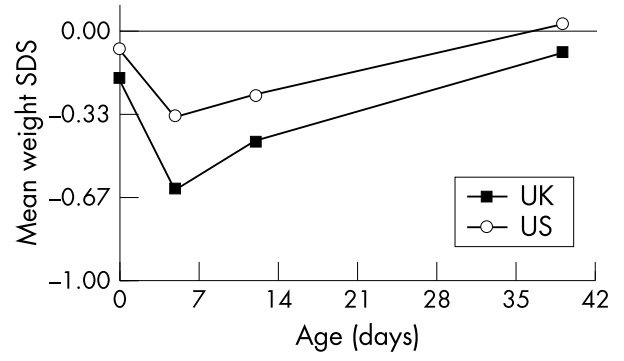

Figure 1 Neonatal weight standard deviation scores (SDS), UK and US standards compared. $0=50$ th centile; $-0.67 \mathrm{SDS}=25$ th centile.

represented, this not being a standard age for weighing. The weights obtained appeared to be representative: there was little difference in the levels of deprivation between those weighed or not weighed at this age, or evidence that those with missing data had systematic differences in weight at birth. However, it is known that in general those babies who are weighed most tend to be growing least well, ${ }^{12}$ so it is possible that the average weight loss at 5 days has been slightly overestimated as a result. Those not weighed at later ages did have higher levels of deprivation and were slightly lighter at birth, but as the proportion of missing values at these ages was small, any effect should be slight. Another potential source of bias would be if ill children had not been weighed because they were in hospital. However, of the 32 children admitted to hospital during the first 3 weeks of life, $18(56 \%)$ had weights returned at age 5 days, similar to the proportion in those not admitted $(51 \%)$.

A limitation is that data are not available at the time of maximum weight loss, thought to be on days $2-3 .{ }^{5}$ It is not clear whether a $1.4 \%$ loss at 5 days is consistent with the predicted $4-7 \%$ loss three days earlier. However, for clinical purposes, a low point reached early on is less important than persisting loss over time. These data supply norms for ages when children are routinely seen by health professionals for screening purposes, when a judgment may need to be made about whether weight gain is normal.

The strength of the study is the large numbers, allowing estimates of normal limits. No previous study with data from birth has included more than 150 children, and most tended to be selected in some way, predominantly being hospital based. This study did not exclude children with major health problems, but the prospective nature of the study meant that we could show that those children with the largest weight loss did not have major organic disease.

The weights were not collected under research conditions, but careful cross checking against other data recorded for the

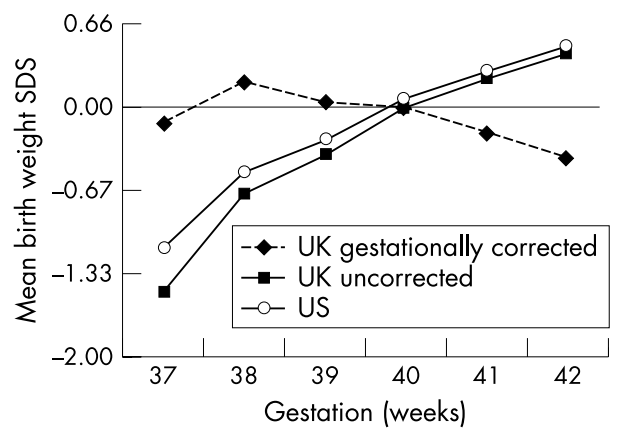

Figure 2 Birth weight standard deviation scores (SDS) by gestation, US references compared with UK, with and without gestational correction. $0=50$ th centile $;-2$ SDS $=2$ nd centile. child ensured that extreme erroneous values would be a rarity. Routinely collected weights have been a powerful resource for previous studies ${ }^{13}$ and make it possible to assemble a much larger data set than previous studies. These data are consistent with other studies at similar ages. A large US study ${ }^{14}$ with weights at 8,14 , and 28 days found very similar results; the mean weights given in the paper, translated into SDSs compared with the UK 1990 reference, produce means of $-0.54,-0.48$, and -0.18 SDS respectively. A much smaller Australian study measured children ${ }^{15}$ at birth and at 10 days and also produced similar values (means of -0.09 and -0.47 SDS respectively compared with the UK reference).

These findings suggest that the tools we currently have for assessing weight gain in infancy are not suitable for use in the first month. Both the US and UK charts give the impression that all children are below the norm in the first fortnight, as well as misrepresenting the growth of children born at the extremes of "term" gestation.

The US standard fits this cohort better from birth to 12 days than the UK standards, but less well at 6 weeks. Overall, however, the similarities in degree of fit are greater than the differences between the two standards, which suggests that British and US children show comparable similar early growth.

\section{CONCLUSIONS}

These data show that the traditional guidance that babies regain their birth weight by the age of 2 weeks is broadly true and that a sustained loss of more than $10 \%$ of birth weight is unusual, although not commonly associated with underlying pathology. However, weights plotted in the first month present a misleading picture of actual weight gain, because no account is taken of neonatal weight loss in current (or previous) weight charts. This would suggest that modifications to the UK and US growth references to allow for neonatal weight loss are desirable, as well as clarification of the role of gestational adjustment. In the meantime, users of charts should be warned of their major limitations in the first 3 weeks of life.

\section{ACKNOWLEDGEMENTS}

Our thanks to Jane Jarvis, Jayne Kelly, Anne Trail, Alison Smith, and Ann Pattinson for their work on the study, to Phillip Lowe for computing support, and to John Reilly and Lawrence Weaver for their comments on the paper. The study would not have been possible without the invaluable support of the midwives and health visitors of Gateshead and the loyal participation of all the parents in the study.

\section{Authors' affiliations}

C M Wright, K N Parkinson, Department of Child Health, University of Newcastle upon Tyne, Newcastle upon Tyne, UK

Grant support: Henry Smith Charity, Child Growth Foundation.

\section{REFERENCES}

1 Maisels J, Gifford K, Antle C, et al. Jaundice in the healthy new born infant: a new approach to an old problem. Pediatrics 1988:81:505-11.

2 Avoa A, Fischer P. The influence of perinatal instruction about breastfeeding on neonatal weight loss. Pediatrics 1990;86:313-15.

3 Enzunga A, Fischer P. Neonatal weight loss in rural Zaire. Ann Trop Paediatr 1990:10:159-63.

4 Marchini G, Stock S. Thirst and vasopressin secretion counteract dehydration in newborn infants. J Pediatr 1997;130:736-9.

5 Bishop N, King F, Lucas A. Linear growth in the early neonatal period. Arch Dis Child 1990;65:708-10.

6 Wright C, Booth I, Buckler J, et al. Growth reference charts for use in the United Kingdom. Arch Dis Child 2002;86:11-14.

7 Freeman JV, Cole TJ, Chinn S, et al. Cross sectional stature and weight reference curves for the UK, 1990. Arch Dis Child 1995;73:17-24. 
8 Kuczmarski R Ogden C Grummer-Strawn L, et al CDC growth charts: United States. 314. 2000. Hyattsville, MD: National Centre for Health Statistics, 2000.

9 Townsend P, Phillimore P, Beattie A. Health and deprivation: inequality and the North. London: Croom Helm, 1988.

10 Brace RA. Fluid distribution in the foetus and neonate. In: Polin RA, Fox WW, eds. Fetal and neonatal physiology. Philadelphia: WB Saunders, 1992:1288-98.

11 Kuzawa C. Adipose tissue in human infancy and childhood: an evolutionary perspective. Yearb Phys Anthropol 1998;41:177-209.
12 Wright C. Who comes to be weighed: an exception to the inverse care law. Lancet 1997;350:642.

13 Wright CM, Waterston A, Matthews JNS, et al. What is the normal rate of weight gain in infancy? Acta Paediatr 1994;83:351-6.

14 Nelson S, Rogers R, Ziegler E, et al. Gain in weight and length during early infancy. Early Hum Dev 1989;19:223-39.

15 Shepherd R, Oxborough D, Holt T, et al. Longitudinal study of the body composition of weight gain in exclusively breast-fed and intake-measured whey based formula-fed infants to age 3 months. J Pediatr Gastroenterol Nutr 1988:7:732-9. 